\title{
SMART GOVERNANCE IN THE CAPITAL CITY OF WARSAW WITH THE USE OF ICT AND GEOINFORMATION TECHNOLOGIES
}

\author{
D. Gotlib ${ }^{1}$, T. Kulisiewicz ${ }^{2}$, M. Muraszkiewicz ${ }^{3}$, R. Olszewski $^{4}$ \\ ${ }^{1}$ Warsaw University of Technology, Faculty of Geodesy and Cartography, Poland - dariusz.gotlib@pw.edu.pl \\ ${ }^{2}$ Polish Chamber of Information Technology and Telecommunications, Poland - tomasz.kulisiewicz@ piit.org.pl \\ ${ }^{3}$ Warsaw University of Technology, Faculty of Electronics and Information Technology, Poland - mietek@n-s.pl \\ ${ }^{4}$ Warsaw University of Technology, Faculty of Geodesy and Cartography, Poland - robert.olszewski@pw.edu.pl
}

\section{Commission VI, WG VI/4}

KEY WORDS: Smart City, Smart Governance, ICT, Geoinformation, Structural Transformation.

\begin{abstract}
:
The article presents the results of work carried out as part of the "Objectives of the SMART CITY program in the capital city of Warsaw" project run at the request of the Digitisation Bureau of the Warsaw City Hall by a design team from the Warsaw University of Technology in cooperation with Comtegra S.A. company. The first part shows the analytical assessment of systems, services, and solutions used in Warsaw in September and October 2017 as well as a SWOT analysis of weaknesses, opportunities, and threats of transforming Warsaw into a smart city. The second part of the article presents reasons and objectives of the transformation, as well as a general conceptual framework for Warsaw as a smart city. The study focuses on describing the critical processes that should take place in the structures of the city; principles and future directions for the model of organisation: services and solutions, actions and assistance that are already in progress or will be undertaken in the first stages of transforming the capital city of Warsaw into a smart city. The solution proposed by the authors of the article below concerning the transformation of the Polish capital into a smart city is currently being implemented by the City Hall of Warsaw in cooperation with Deloitte.
\end{abstract}

\section{INTRODUCTION}

Among numerous definitions of a smart city, the definition from the dictionary developed by the British Standards Institution for certification and standards-related services is of particular importance. According to the BSI PAS 180:2014 specification, a smart city means "the effective integration of physical, digital and human systems in the built environment to deliver a sustainable, prosperous and inclusive future for its citizens." Whereas Manville (2014) assumes that a smart city is a city where "public issues are solved using information and communication technologies (ICT) with the engagement of various stakeholders who act in partnership with the city authorities."

Documents from the joint work of Study Group 5 ITU-T ${ }^{1}$ and $\mathrm{UNECE}^{2}$ include a definition that emphasises the use of Information and Communication Technologies solutions in creating a sustainable smart city: "a smart, sustainable city is an innovative city that uses information and communication technologies (ICTs) and other means to improve quality of life, the efficiency of urban operation and services, and competitiveness, while ensuring that it meets the needs of

\footnotetext{
${ }^{1}$ ITU-T - Telecommunication Standardisation Sector (ITU-T) of the International Telecommunication Union.

${ }^{2}$ UNECE - the United Nations Economic Commission for Europe (UNECE); one of the regional commissions of the United Nations.
}

present and future generations with respect to economic, social and environmental aspects.",3

The Organisational Rules of the Warsaw Digitisation Bureau, which explain the concept of a smart city, have also emphasised these aspects: a smart city "should be understood as a dynamic network of mutually communicating and interacting people, resources, structures, and services, in which new, smart techniques and technologies, as well as innovative methods, are used to improve the quality and organisation of life."

Authors of several other definitions emphasise the use of ICT solutions for innovative cooperation between administration and residents. In "Smart Cities Study: International Study on the Situation of ICT, Innovation and Knowledge in Cities," a smart city has been defined as a city that "uses information and communications technology to make both its critical infrastructure, its components and utilities more interactive, efficient, making citizens more aware of them." The authors stress that a city can be considered as a smart one only when it simultaneously invests in technologies, human capital, and communication infrastructure to promote sustainable economic development and high quality of life (e.g. it enables the management of natural resources through civic participation). Nicos Komninos offers a similar approach to this problem: a smart city is "a territory with high capacity for learning and innovation, creative, with research and development

\footnotetext{
3 http://www.itu.int/en/ITU-

T/focusgroups/ssc/Pages/default.aspx

(accessed on May 10, 2019).
} 
institutions, higher education, infrastructure and digital communication technologies, as well as a high level of management performance." Thus, in this approach, it is vital to draw a distinction between a modern city and a smart city. According to the authors of the article, using ICT, geoinformation systems, and knowledge bases is a necessary but insufficient condition for talking about the creation of a smart city. What is crucially important for this process is achieving synergy between different systems operating and implemented in the city.

Andrea Caragliu takes a similar approach, pointing out that a smart city is such an organism in which "investments in human and social capital and traditional (transport) and modern infrastructure (based on ICTs) fuel sustainable economic growth and high quality of life, with a wise management of natural resources through participatory governance."

In a smart city, solutions are created and implemented in such a way as to ensure coherent and active cooperation of information systems and the interoperability of IT systems. As a result, the municipal administration receives tools that not only enable the adaptation to the challenges, phenomena, and changing environmental conditions, but also the forecasts about trends and phenomena, the prevention of unfavourable phenomena and the use of favourable phenomena or conditions.

Taking into account the aforementioned conceptual and methodological assumptions, the authors of the study assumed that for the transformation of Warsaw into a smart city it is necessary to define the conceptual framework of the long-term process of structural transformation and to define the basic methods or tools required to implement the process of creating a smart city.

It must be stressed that the process of transformation requires considering strictly technological possibilities of the designed ICT systems as well as the existing legal, institutional, and social conditions. Consequently, the nature of the structural transformation process should be evolutionary; it consists of long-term measures with dynamics that vary over time.

\section{RESEARCH METHODOLOGY AND ANALYSIS OF EXISTING IT SOLUTIONS IMPLEMENTED IN} WARSAW

Among others, the following documents constituted the basis for researching the current state of Warsaw:

- $\quad$ Stocktaking of activities in line with the SMART CITY idea in Warsaw (AS IS): a sheet that systematically details over 300 systems and measures adopted and conducted in the city of Warsaw (developed by a team from Comtegra S.A. company in October 2017).

- Warsaw as a smart city: a catalogue of solutions established solutions, adopted measures, and implemented projects related to the smart city idea (document prepared by the Economic Development Bureau of the Capital City of Warsaw, Department of Economic Promotion in September 2017).

- A register of internal systems provided by the Digitisation Bureau: a compilation of over 100 systems and internal registers that do not provide online information to users outside the organisational units of the Warsaw City Hall and entities or affiliated companies.
Because ICT systems play a vital role in the transformation of the city, the analysis of the present state was carried out primarily with regards to these systems. The analysis adopted a methodology that uses the classification of analysed IT systems according to the following criteria: the presence of data validation mechanisms, the accessibility for the disabled, the level of data openness, the completeness of metadata, the level of IT system's "smartness," the use/presentation of geoinformation, the presence of mechanisms useful in the transformation.

The analysis has also included the so-called social data sources and information services which indicate, among other things, the degree of application of ICT solutions developed by the Warsaw City Hall and the level of interest in accessing the socalled open data provided by the city authorities.

The authors of the research regarded the criteria "The "smartness' of the IT system" and "The use of geoinformation" as particularly important in the analysis of existing solutions.

When evaluating the "smartness" of systems, two specific criteria were considered:

1) the degree of connection with other systems:

- systems logically linked to other systems and sharing data,

- independent systems or systems minimally dependent on other systems;

2) the degree of the functional and algorithmic complexity of a system:

- complex systems equipped with advanced applications and algorithms (e.g. artificial intelligence) that enable the implementation of at least the basic characteristics of the "smartness" mentioned above,

- systems that perform tasks without any "smart" characteristics.

"The use of geoinformation" criterion was essential for evaluating the potential of current systems, because-according to the authors of this article - the majority of city systems have, or may have, a spatial reference. Thus, geoinformational identification may serve as the basis for creating an integrated platform for target ICT systems comprising the starting point of a smart city in Warsaw.

The group of critical solutions for the city and its transformation into a smart city involves such systems as:

- Vehicle Position Management System [System Zarządzania Pozycjami Pojazdów] - Warsaw Transport Authority [Zarząd Transportu Miejskiego];

- Passenger Information System [SIP System Informacji Pasażerskiej] - Warsaw Tramways [Tramwaje Warszawskie];

- a two-way contact channel for the authorities and residents of the city - Warsaw 19115 Municipal Contact Centre (Warsaw City Hall);

- $\quad$ an integrated traffic management system - Municipal Road Authority [Zarząd Dróg Miejskich];

- Veturilo - Warsaw public bike (Warsaw City Hall);

- Infoulice [infostreets] Warsaw (Warsaw City Hall);

- Infokorki [infotraffic] (Warsaw City Hall);

- $\quad$ parking meters (Municipal Road Authority),

- TramBus (Municipal Bus Company) [Miejskie Zakłady Autobusowe],

- $\quad$ participatory budget (Warsaw City Hall), 
- a system for booking appointments in the capital city of Warsaw (Warsaw City Hall);

- a municipal video surveillance system (Warsaw City Hall);

- a municipal alert system for the residents (Warsaw City Hall);

- Central Spatial Database [Centralna Baza Danych Przestrzennych] and mapping systems of the capital city of Warsaw Warszawa (Warsaw City Hall);

- $\quad$ systems supporting transport solutions: Traficar, Panek CarSharing, UBER, Jakdojade.pl;

- $\quad$ applications for buying public transport tickets and paying for parking spaces (skycash, mPAY, moBiLET).

Systems and registers used in the city of Warsaw include various issues for which they were, and are, created and exploited: from financial data processing, through personal records and registers, civil records, to sophisticated control and geoinformation systems. With such a variety of issues, it is impossible to achieve complete semantic interoperability. It is, however, possible to frame a set of concepts defined in a uniform and consistent way to maintain the minimum semantic interoperability (congruence of concepts).

The level of data openness of a vast majority of researched information services and websites is not high; they present information as HTML code or as PDF documents, sometimes in text editor formats (usually DOC/DOCX, sometimes ODT). One of the more open systems is "Otwarte dane - czyli dane po warszawsku" [Open Varsovian data] - a service available at https://api.um.warszawa.pl/, which contains detailed and unified information and metadata of shared collections and records, along with access to the API. At least 50 of the catalogued systems/websites present or use spatial data.

Due to the multitude and inconsistency of solutions, a user does not attain many pieces of useful geoinformation, which also happens because of the inconsistency of search engines (on the one hand, based on Google, and the other - on official data). In addition to this, there are semantic inconsistencies: different companies or institutions have separately created many websites for various institutions and organisations. As a result, some areas of the city are "covered" by several systems or geospatial services (redundancy), which are not necessarily consistent or even interoperable, while other areas remain "blank spots," not providing data or information on the given area.

What is very important is that information from the Central Spatial Database of the capital city of Warsaw is made increasingly more available via web services (under the OGC standards).

The analysis of existing systems concludes that the capital city of Warsaw currently has many ICT and infrastructural systems typical for cities aspiring to become a smart city. However, the systems have not been created following a uniform vision and the concept of building "the Smart City of Warsaw"; instead, their creation has been siloed and independent, in natural and not fully controlled processes of consecutive implementation of modern technological and organisational solutions.

The systems that are currently available and operative, however, may constitute a starting point for the construction of an integrated smart city platform in Warsaw, which gathers IT solutions and systems. ICT solutions and various infrastructural solutions implemented by the city have significant functional potential. The main problem with existing solutions is that they are siloed and partially redundant information-wise; all the while, there is no integrative smart city platform. What is also essential is the unidirectionality of existing systems: information and geoinformation services created by the City Hall primarily fulfil the function of communication, but they do not include modules that enable the creation of feedback channels for civic information. The moulding of the capital city in the spirit of Human Smart City requires using modern technologies as well as supporting the development of an open geoinformation society.

\section{OBJECTIVES OF THE SMART CITY PROGRAM IN THE CAPITAL CITY OF WARSAW}

The conducted research has drawn attention to the difference between a modern city, in the ordinary meaning of the term, namely a city that implements a variety of new organisational, technical, and financial solutions in a traditional way, and a smart city, in which various solutions are built and implemented in an integrated manner to achieve the goals. An essential difference in defining these approaches is the synergy resulting from the integration of interoperable systems and services that make up the ecosystem of a smart city.

In a smart city, solutions are created and implemented in a way that ensures coherence and proper cooperation of information systems and the interoperability of IT systems.

One should bear in mind that creating a smart city is a process that cannot be identified with reaching a static "target state," as it has been cogently expressed in the statement by the British Department for Business, Innovation and Skills. According to this institution, a smart city is not static, instead, it is a process; a smart city should enable every citizen to engage; by bringing together hard infrastructure, social capital, and digital technologies, cities become more "liveable" and resilient and, hence, able to respond more quickly to new challenges (UK Department for Business, Innovation and Skills, 2013).

The process of transforming Warsaw into a smart city should enable the implementation of the vision's critical elements and the strategic goals contained in the "Strategy \#Warszawa2030" project, e.g. an engaged community, comfortable locality, functional space, and an innovative environment. The SWOT analysis made in "Strategy \#Warszawa2030" indicates the necessity of Warsaw's evolution into a friendly place, as well as into an open metropolis inhabited by active residents. Realising this vision requires the development and implementation of a program for transforming Warsaw into a smart city and the adoption of several infrastructural, organisational, and technological solutions designed as part of the capital city's process of transformation into a city aspiring to become a smart metropolis of European significance.

\subsection{Detailed objectives}

The authors assumed that the process of transformation should proceed according to the following schema: from vision through strategy, programme, implementation projects, to the final outcome.

Because of its vastness and long-term nature, the process of transforming Warsaw into a smart city should be designed and 
formulated in the form of a city transformation programme that can be called a Smart City Programme.

As a result of the work by organisations such as the BSI Group and ISO, several documents have been created to guide or organise creating smart city solutions. When taking measures related to the transformation of Warsaw into a smart city, it is vital to pay special attention to:

1) BSI PAS 180 "Smart cities - Vocabulary"

2) BSI PAS 181 "Smart city framework - Guide"

3) BSI PAS 182 "Smart city concept model - Guide"

4) PD 8100 "Smart city overview"

5) PD 8101 "Smart cities. Guide to the role of the planning and development process"

6) ISO 37120: 2015-03 "Sustainable development of communities - Indicators for city services and quality of life"

In respect of defining the role of spatial data and geoinformation technologies in the construction and development of a smart city, ISO standards in the field of geographic information (19100 series), studies by the Open Geospatial Consortium (OGC), as well as legal acts and guidelines related to the implementation of the INSPIRE Directive in Europe (which is the starting point for spatial information infrastructure) is particularly important. The authors of this study assumed that a spatial reference could constitute an integrative geoinformation platform for other smart city systems in a city.

For an effective mapping of resources, including human resources, and their management by means of adapting the city's technology and its digital resources to an integrated approach based on the "non-siloed" attitude - defined in the transformation of the city's operational model - it is crucial to develop and accept the vision at the highest level and the architecture of a smart city system for the future use of interoperable technologies by the city.

An active, continuous, and balanced transformation of Warsaw into a smart city must fulfil the condition of connecting all the networks comprising the technical infrastructure, and associated automation or control systems into coherent information and IT infrastructure of the city. This infrastructure will serve as a platform that integrates information resources, services, and applications, while the systems that manage this platform collecting, processing, and sharing collected data - will make up the city's operating system, analogous to computer operating systems, consistently controlling the entire city as a system. The condition for efficient integration of automation and control systems of the "hard" technical infrastructure is - similarly to information systems - ensuring their interoperability and equipping them with obligatory metadata describing key parameters and structures of these systems and data structures.

Simultaneously, what is crucial for the functioning of a smart city is creating an innovative and friendly architectural infrastructure as well as smart urbanistic solutions. Such solutions should be supported by modern technological solutions that enable using massive data about the city and the needs of its inhabitants in these processes. Modelling the movement of residents and visitors, analysing the urban air corridors, acoustic modelling, insolation modelling, modelling data from social participation systems, analysing real estate market and existing network solutions (infrastructure) - these are just some aspects of the modern process of planning a smart city development and creating the spatial order.

Regardless of the organisational structure, the full interoperability of all information systems operating in the entire organisational structure of the city hall is crucial - both semantic (regarding objects and information relations, the common ontology of concepts) and syntactic (interoperability of structures and data formats). It is the condition for an effective transformation of a city into a smart city.

Effective implementation of this process should include the following measures:

- Introducing the requirement of interoperability for created systems: the requirement of interoperability embedded in the architecture of the systems at their design ("by design"), for new systems, they must be in the assumptions and specifications of building or ordering of systems.

- Introducing the requirement of interoperability for existing systems - the easiest way is to implement the requirement when upgrading, rebuilding or transferring systems to other system environments or hardware platforms. What requires the most amount of work is increasing the interoperability of systems used on an ongoing basis, which usually entails middleware, information brokers, and other solutions that enable systems to cooperate on shared platforms.

\section{SELECTED PROPOSALS FOR DETAILED SOLUTIONS}

For the process of evolutionary creation and operation of Warsaw as a smart city - called the Smart City Programme - the digitisation and cooperation of all potentially interested entities are crucial. Developing a smart city should ensure the proper creation of spatial order, informed implementation of new technological solutions, and a shared vision for the social and economic development of the city put together by the primary stakeholders.

\section{Sustainable model of smart city development}

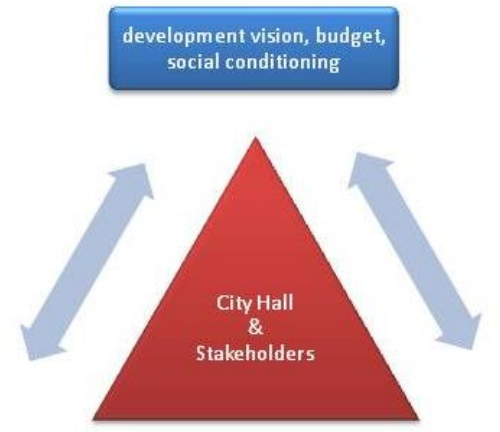

Spatial planning Technology

Figure 1. Sustainable model of smart city development (authors' original work)

The implementation of the comprehensive program of the digital transformation of Warsaw is a multifaceted process, which should not be understood solely as an application of ICT 
technologies - even if they are incredibly innovative. One element of transforming Warsaw into a smart city is realising the vision of the city's development as a friendly place, and also an open metropolis inhabited by active residents; a vision expressed in the "Strategy \#Warszawa 2030" project. The authors assume that a friendly place means "a wealth of space, stemming from a skilful merger of tradition and modernity, urban and natural environments, the local combined with the metropolitan, offering the comfort of life and favourable conditions for being active." The implementation of such a vision of a friendly place - in combination with the simultaneous shaping of an open civic society (active citizens) and the creation of an open metropolis with a European significance - requires making enormous efforts towards creating a spatial order in the capital city. Thus, the process of spatial planning should lead to shaping a city with a hierarchical functional and spatial structure in the so-called sustainable model (Figure 1).

It should be emphasised that the analysis of a significant volume of urban big data requires the use of complex algorithms of exploratory spatial data mining and the harmonisation of existing data resources. Also, it is essential that the process of spatial planning of Warsaw as an open metropolis uses not only modern analytical tools but also reliable and recent spatial data, including $3 \mathrm{D}$ data. Thanks to their analysis, it will be possible to shape (in a broader sense) the spatial order in the capital but also provide detailed WHATIF predictive analyses. Such examples include a 3D visibility analysis associated with designing new buildings, analysis of atmospheric pollution and smog propagation in the city, the determination of urban risks for the existing urban air corridors, the creation of a three-dimensional map of acoustic hazards, and the like.

\subsection{Innovative solutions for a smart city in Warsaw}

As a result of the work, several functions, services, and solutions have been proposed that characterise a smart city. Those that would set Warsaw apart from other cities around the world and in Europe, implementing programmes for building and transforming urban structures into smart cities deserve special attention. The following are among them:

- Smart, automated interfaces for information access.

- Smart hotlines and virtual services for residents.

- An integrated system for analysing the residents' mobility.

- An integrated information system.

- Social geoparticipation (citizens-as-sensors).

Figure 2 shows a diagram of the ecosystem of ICT solutions for the city of Warsaw. The transformation of systems should strive to organise their development, harmonisation, and introduction of connections through the Interoperational ICT Platform while using the Integrative Geoinformation Platform (GEO). The interoperable ICT platform should fully integrate systems critical to a smart city. At the same time, many of them (depending on their functionality) should have standardised access to the geoinformation platform, which should also be closely connected to the city's ICT platform. However, as the diagram shows, it does not limit the development of various types of systems associated only with the ICT or geoinformation platform, or completely independent.

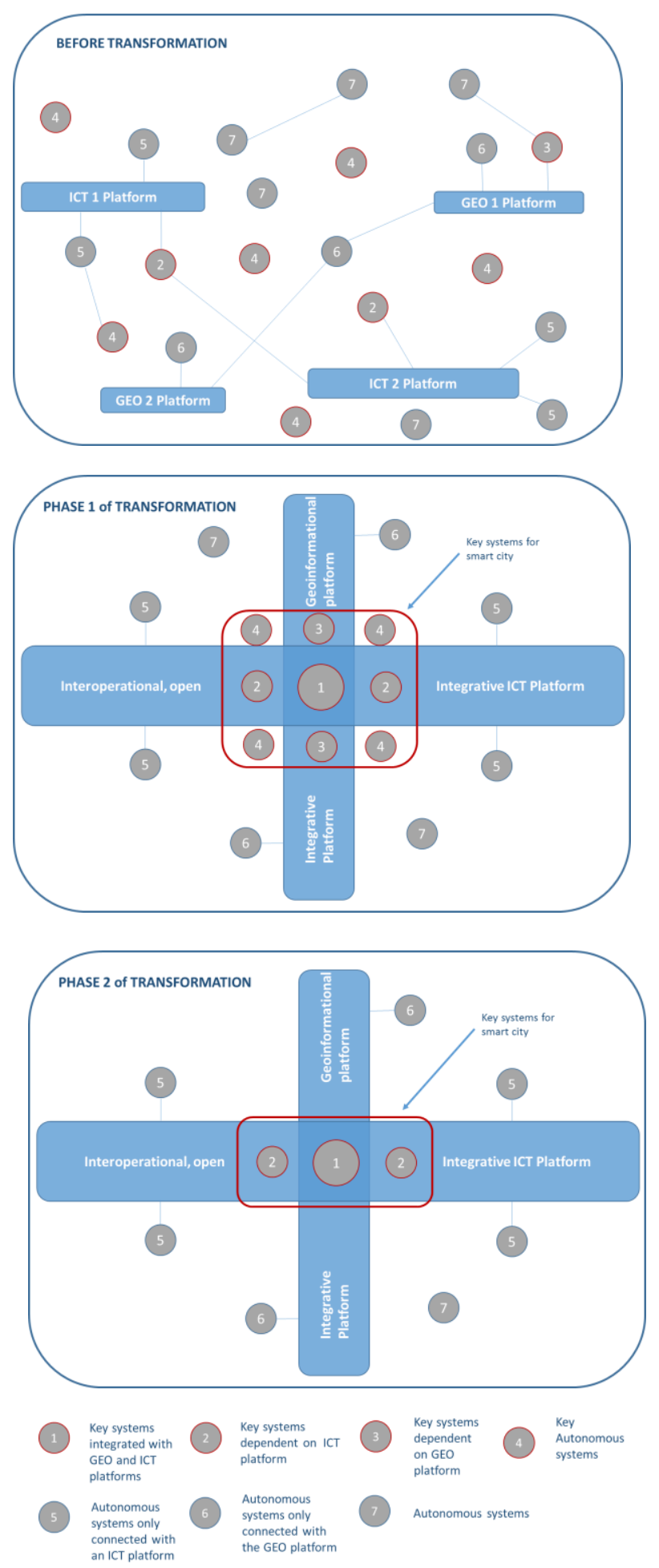

Figure 2, 3, 4. Diagrammed transformation of the ICT solutions for Warsaw: from unordered to integrated systems

The harmonisation of IT systems with the smart city concept and solutions, the presence of metadata and a unified and formalised mode of reporting new projects are all imperative for IT systems for the smart city of Warsaw. Consequently, it will ensure the harmonisation of the current and created solutions, as well as their interoperability in line with the smart city concept. 
Harmonisation may be implemented through the certification of systems aspiring to the "smart city" title; the certification should consist in the evaluation of the systems' features. Only a system that meets the defined necessary conditions may receive a "smart city" certificate. Depending on the degree to which the features meet the conditions of a smart city, there may be two or more levels of certification. This measure aims at stimulating a stepwise transformation; the transformation of existing systems into solutions fitting into the general smart city concept for the city of Warsaw. The process of certification also raises awareness regarding a specific solution or a system and its consistency with the concept of a smart city; it also encourages the cooperation of various stakeholders, ultimately reducing the silo-like quality of existing solutions.

Introducing a system of metadata collection (data about systems and databases) aims at facilitating the coordination of the construction and development of all the systems operating for the benefit of the capital city of Warsaw.

The following pieces of information should constitute the metadata for the systems:

- the name of the system,

- the creator of the system,

- the system's owner, operator, administrator, and the like,

- general characteristics,

- the purpose of the construction,

- informational and functional scope (including keywords),

- the technology of implementation,

- date of commencement of operation or data sharing,

- period updates,

- versions of a system or data,

- contact details for the managers, and the like.

What is also significant is creating a structure that facilitates the implementation of the proposed smart city solutions in the City Hall (Figure 3). A process of system transformation not supported by the Smart City Council and the Group of Smart City Leaders is impossible. The Council is responsible for coordinating the work of the office's particular organisational units at the management level, while the Group of Smart City Leaders supports the grassroots activities and generate technical initiatives of the office's employees.

The foundation for this type of platform in the city of Warsaw may lie in the existing or designed solutions such as:

- a portal of common e-services,

- 19115 portal,

- a multifunctional city card system - "Karta Warszawiaka" [A Varsovian's Card],

- document management system,

- a project of consolidating municipal websites,

- Taxpayer Service Centre [Centrum Obsługi Podatnika],

- Central Spatial Database,

- "Dane po warszawsku" [Varsovian data] platform.

\subsection{Social geoparticipation}

Implementing smart city solutions in Warsaw requires developing many solutions that enable smart processing of source data and granting access to the processed information, as well as a smart collection of data from the network of urban sensors. Thanks to the constant expansion of this network, it will be possible to collect and process volumes of big data in real time, but it will not ensure obtaining subjective data. Social participation of the capital's residents - regarded as live "sensors" per the idea of citizens-as-sensors (Goodchild, 2007) - is requisite for gathering spatially referred data collected by citizens in the VGI (Volunteered Geographic Information) process.

Appropriately constructed and skilfully advertised geoinformation applications for mobile devices may provide data not only about air pollution or temperature but also about the residents' feelings and opinions. Most of such opinions may be spatially localised, enabling their real-time interpolation and generalisation. Processing of data coming from the system users will enable, e.g. the ongoing modification of the public transport operation, dispatching relevant agencies to the given place of a threat, as well as detecting trends and dependencies in the spatial distribution of information provided by users.

For the implementation of modern ICT and the use of geoinformation tools in Warsaw in the spirit of Human Smart City, it is crucial to support the process of engaging the local community and crowdsourcing, understood as the social gathering of data, opinions, and innovative ideas. This process should apply to the broadly understood idea of social geoparticipation in shaping the vision for the city's development, planning the revitalisation of neglected areas, as well as acquiring and updating data by the residents (the aforementioned idea of citizens-as-sensors). It should also apply to the supporting of the idea of their processing of data, creating and discussing models for developing a smart Warsaw in the process known as Citizen Science. Including the inhabitants, acting as "sensors," in the process of transformation may showcase Warsaw and set it apart from other cities transforming into smart cities. The specific showcase of the vision for the development of Warsaw into a smart city may be the devising of a tool for virtual social debate ("Virtual Agora of Warsaw") between the city's authorities and residents about shaping and developing a smart city in Warsaw.

It is noteworthy that the process of even the most complex data analysis carried out in the city hall is currently limited to the processing of "hard" data, e.g. official data or data from the network of city sensors. Social geoparticipation, and the resulting cooperation, co-decision making and co-management, require employing active forms, such as dedicated geo-surveys - surveys with the capability of indicating places in space. Using modern geoinformation technologies and ICT tools to create geo-surveys and advanced $3 \mathrm{D}$ modelling methods, at times with augmented reality elements, is a necessary but insufficient component of engaging the residents in a smart city. What is crucial to change passive and atomised individuals into an open information society - creating a vision for the development of the capital in the process of social participation - is the liberation of social energy. For the efficiency of this process, it is crucial to achieve synergy between the analysis of "hard" and "soft" data and their combined processing using advanced spatial data mining algorithms. A holistic approach to the issue of collecting and processing spatial data with the participation of the local community will give rise to the aforementioned Virtual Agora of Warsaw as a platform for social debate on co-shaping Warsaw into a smart city. 


\subsection{Integrative Geoinformation Platform}

One of the key elements of an integrated, open, and widely available IT platform proposed by the authors could be an integrative geoinformation platform. Managing a city requires the effective use of spatial information. Currently available data resources of this kind keep becoming bigger and more complex; their optimal use requires the employment of modern geoinformation technologies and the integration with other data and systems. The gains from implementing such solutions can be significant. Nowadays, it is impossible to imagine a smart city and smart city systems without access to high-quality geoinformation. How would one plan a city's development, issue building permits, conduct urban monitoring, manage urban infrastructure, optimise communication, control tourism traffic, react to threats, and so on, without knowing the location of objects, phenomena, and their mutual spatial relations?

The creation of an urban Integrative Geoinformation Platform, whose conceptual assumptions are presented in the study (Gotlib, 2016) and cited below, may offer a solution to the problems mentioned above. An Integrative Geoinformation Platform should be a modern geoinformation system based on geoinformatics methods and technologies, including GIS (geographical information system) technologies. Such a system may serve an integrative role in relation to domain-specific IT systems, presenting the information they contain against a topographic 3D model of the city and many other (official and social) data about space. The developed geospatial platform should be integrated with the cadastral system, geodetic records of the terrain armaments network, spatial development plans, data from the flood protection system, data from road data banks and traffic monitoring systems, data from public transport systems, data on the natural environment, and location data: business facilities, health care facilities, tourist attractions, security-related events, and so on.
Considering the observations above, the platform should also use access interfaces for selected commercial and social systems, e.g. Google Maps or Open Street Maps. Depending on the needs, it will enable the analysis of information using slightly different sources of data; it will be an added value in many situations. What may be particularly important is providing access to Google Street View data, which enables viewing photos of the entire street that had been made by Google's mobile platforms. Due to the specific needs of the city, when creating a smart city, it is vital to consider making personalised documentation and photographic images in frequent cycles adapted to the specificity of Warsaw.

The primary functional tasks for this type of platform are as follows:

- displaying information on the city's space from many data sources: the geodesic and cartographic resources, public institutions resources, resources of commercial companies, and social media resources;

- $\quad$ providing an efficient interface for accessing spatial data about the city;

- making it possible to implement the so-called spatial services, e.g. geocoding, searching for the optimal route to drive or walk to a specific object, making a cross-section of the terrain, calculating the population of a given area, determining the visibility of the area and objects from a given place, calculating the distance and area, calculating the time availability, and the like.

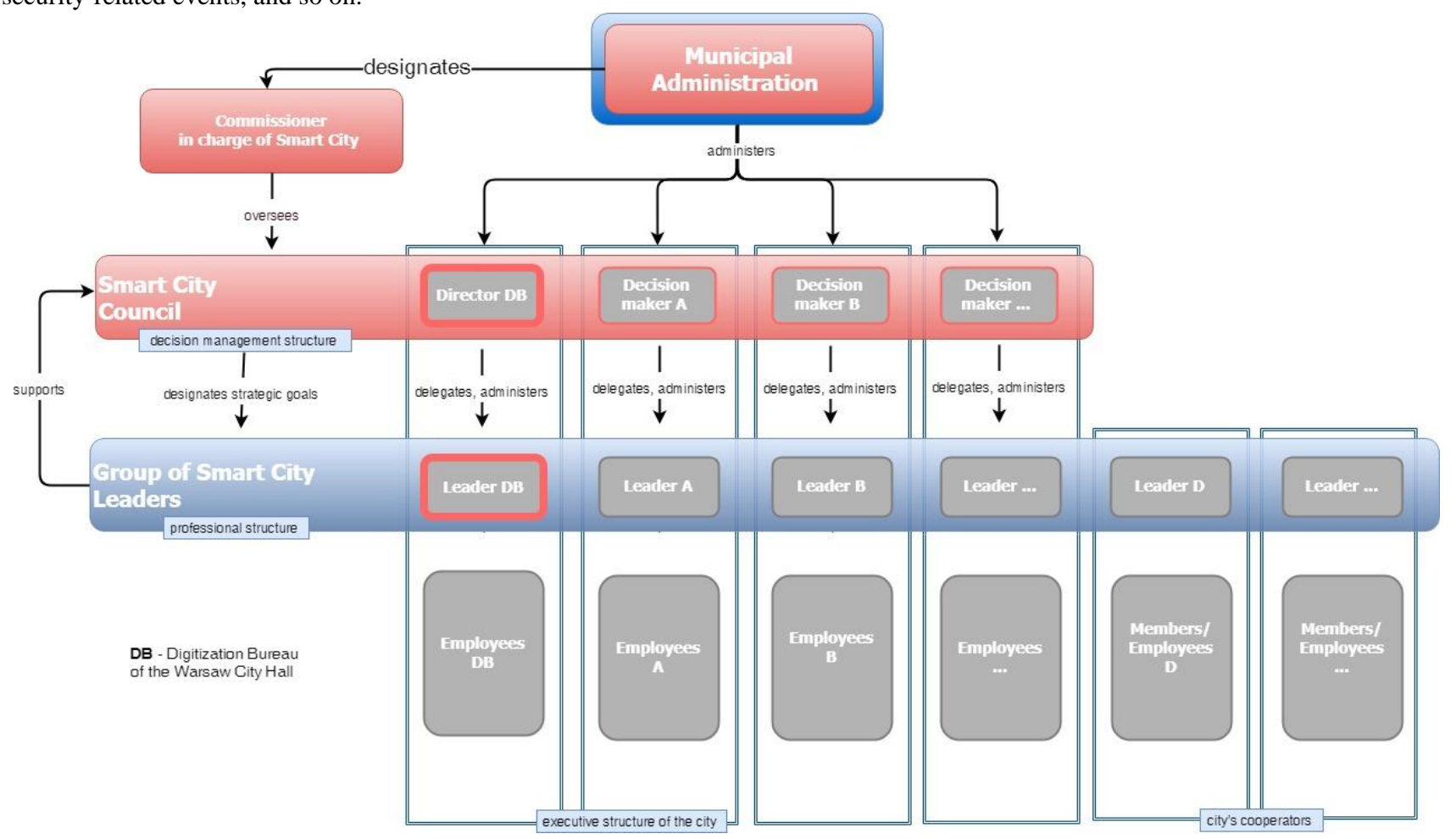

Figure 5. Organisational chart of Smart City Council and Group of Smart City Leaders 


\section{SUMMARY AND CONCLUSIONS}

The conducted research indicates that the foundation for the transformation of Warsaw into a smart city should rest on a unique and interoperable ICT platform that enables the integration of various infrastructural solutions while maintaining the possibility of their autonomous development. In this context, the key issues are innovative infrastructural transport solutions (smart transport systems, passenger information systems, passenger analysis systems, innovative vehicle rental systems), architectural and urbanistic solutions that ensure business development and "friendly locality," and the development of the latest ICT infrastructure and integrated security systems. What is crucially important to the efficacy of implementing an integrative ICT platform in Warsaw is the use of geoinformation as a spatial reference not only to objects but also to dynamic processes and phenomena transpiring in the city.

From the socio-technological perspective, the keynote of Warsaw's strategy may be the development of the concept of "citizens as human sensors." On the one hand, it enables collecting unique data and, then, obtaining unique information from the data; on the other hand, developing a social participation system on an unprecedented scale.

The implementation of the latest technological solutions in a smart city does not stem from the need for modernity but from the need to improve the inhabitants' way of life. Thus, so much importance in the proposal is attached to the development of advanced systems of residents' participation in Warsaw. Defining the needs of the residents will be possible thanks to the smart analysis of data collected through operating participatory platforms (in particular, the advanced analysis of data collected in this manner), as well as activating the officials who have considerable knowledge of the residents' needs (systems reporting innovation, participating in the Group of Smart City Leaders), and implementing solutions supporting the idea of "citizens-as-sensors."

At this stage, the above-mentioned objectives of the vision for developing Warsaw towards a smart city are merely preliminary assumptions made by the authors of this study. All stakeholders should jointly work out the target vision; therefore, this study proposes the organisation of the Smart City Council and the Group of Smart City Leaders for the capital city of Warsaw. These horizontal, instead of siloed, structures (not constituting a separate agency/department in the city, but integrating employees of all the key structures) should recognise the distinct benefits of transformation to all stakeholders and define specific actions in the short- and medium-term.

According to the authors of this study, it should be emphasised that the transformation of Warsaw into a smart city will not be a process that will culminate in achieving a particular static state; the physical, digital, and social systems mentioned in the definition above are continually evolving. Therefore, it is vital to understand the structural transformation of a city towards a smart city as a process of transformation, not a specified target state. It is a process that will consist in achieving many different objectives (levels) in different areas, wherein the desired goals and levels will be dynamically changing, depending on the condition and needs of the city and its economy, development of technical infrastructure, changes in the management structures of the municipal administration, and many other factors. Accordingly, it will be necessary to modify the desired goals, directions, as well as the range of transformative measures, and to develop methods of measurement or indicators that will enable monitoring of the process of transformation and evaluating the effectiveness of the measures taken.

\section{ACKNOWLEDGEMENTS}

We want to express our gratitude to Comtegra S.A. company for the invitation to implement the project, the development of a detailed inventory of the systems in Warsaw, and an effective cooperation, and to the Warsaw City Hall for their substantive cooperation and granting us access to the materials.

\section{REFERENCES}

Azkuna, I. (2012). Smart Cities Study: International Study on the Situation of ICT, Innovation and Knowledge in Cities. UCLG Committee of Digital and Knowledge-based Cities: accessed 12/04/2019 http://www.uclgdigitalcities.org/app/uploads/2015/06/en_smartcitiesstudy.pdf.

Batagan L. (2011). Indicators for economic and social development of the future smart city, Romania: Journal of Applied Quantitative Methods, Vol. 6 Issue 3

BSI Group. (2014, 03 11). BSI Group. PAS 181 Smart city framework: https://www.bsigroup.com/en-GB/smartcities/Smart-Cities-Standards-and-Publication/PAS-181-smartcities-framework/ accessed 16/05/2019

Caragliu, A., Del Bo, C. i Nijkamp, P. (2011). Smart cities in Europe. Journal of Urban Technology, 18(2), pp. 65-82.

Ching T.Y., Ferreira J. (2015). Smart Cities: Concepts, Perceptions and Lessons for Planners in: Planning Support Systems and Smart Cities, Springer

Dirks S., Keeling M., Dencik J. (2009). How Smart is your city? Helping cities measure progress, IBM Global Business Services Government Executive Report, IBM Institute for Business Value, http://public.dhe.ibm.com Accessed 26/05/2019

Gotlib. D., Olszewski, R. (2016). SMART CITY. Informacja przestrzenna $\mathrm{W}$ zarządzaniu inteligentnym miastem, Wydawnictwo Naukowe PWN SA, ISBN 978-83-01-18478-0

Giffinger R., Fertner C., Kramar H., Kalasek R., PichlerMilanović N., Meijers E. (2007). Smart Cities - Ranking of European Medium-Sized Cities, Research Report, Vienna University of Technology

Komninos, N. (2002). Intelligent Cities: Innovation, Knowledge Systems and Digital Spaces. Londyn: Spon Press.

Manville, C. et. al. (2014). Mapping Smart Cities in the EU: http://www.europarl.europa.eu/RegData/etudes/etudes/join/201 4/507480/IPOL-ITRE_ET\%282014\%29507480_EN.pdf

Mumford L. (1968). The City in History: Its Origins, Its Transformations, and Its Prospects, Mariner Books

UK Department for Business, Innovation and Skills. $(2013,10)$. Smart Cities: Background Paper:

https://www.gov.uk/government/uploads/system/uploads/attach ment_data/file/246019/bis-13-1209-smart-cities-backgroundpaper-digital.pdf Accessed 07/05/2019 